This item was submitted to Loughborough's Research Repository by the author.

Items in Figshare are protected by copyright, with all rights reserved, unless otherwise indicated.

\title{
Ambience in social learning: student engagement with new designs for learning spaces
}

PLEASE CITE THE PUBLISHED VERSION

http://dx.doi.org/10.1080/0305764X.2012.676627

\section{PUBLISHER}

(c) University of Cambridge, Faculty of Education

\section{VERSION}

AM (Accepted Manuscript)

\section{PUBLISHER STATEMENT}

This work is made available according to the conditions of the Creative Commons Attribution-NonCommercialNoDerivatives 4.0 International (CC BY-NC-ND 4.0) licence. Full details of this licence are available at: https://creativecommons.org/licenses/by-nc-nd/4.0/

\section{LICENCE}

CC BY-NC-ND 4.0

\section{REPOSITORY RECORD}

Crook, Charles, and Gemma L. Witcomb. 2019. "Ambience in Social Learning: Student Engagement with New Designs for Learning Spaces". figshare. https://hdl.handle.net/2134/19035. 


\title{
Ambience in social learning: student engagement with new designs for learning
} spaces

\section{Charles Crook}

University of Nottingham

Gemma Mitchell

Loughborough University

Author Note

This research was funded by the University of Nottingham CETL for Integrative Learning and received helpful support and input from Angela Smallwood and the Centre staff.

Correspondance concerning this article should be addressed to Charles Crook, School of Education, University of Nottingham, Nottingham, NG8 1BB.

Contact: charles.crook@nottingham.ac.uk

\begin{abstract}
An imperative to develop the social experience of learning has led to the design of informal learning spaces within libraries. Yet little is known about how these spaces are used by students or how students perceive them. Field work in one such space is reported. The general private study practice of undergraduates was captured through audio diaries, while activity in the learning space was directly observed, and students provided reflective perspectives in focus groups and through spot conversations. Results suggest such spaces are popular and yet stimulate limited group work. Yet other, less intense, forms of productive collaboration did occur and a taxonomy of four such types of encounter is offered. Of particular importance to students was access to a 'social ambience' for study. The results encourage institutions to design for a mixed economy of student choice over learning spaces and to consider modes of encouraging diversity in their use.
\end{abstract}




\section{Ambience in social learning: student engagement with new designs for learning spaces}

Agendas for enriching the experience of formal education often consider refreshing the material design of those spaces in which students learn (Comber \& Wall, 2001; Rudd, Morrison \& Facer, 2006). For instance, this became a prominent driver for the UK government’s ‘Building Schools for the Future’ programme (Woolner, Hall, Higgins, McCaughery \& Wall, 2007). Yet there is scant research evidence documenting how students and teachers engage with such new designs. The present report will contribute to this literature by considering how the personal study practices of university students harmonise with one particular configuration for a learning space: namely, an open library area. Broadly, this is a space that invites conversation, is flexibly furnished, and is well resourced with shareable digital technology.

Closer scrutiny of arguments for renewing learning spaces suggests that one recurring motive is the ambition to create more favourable conditions for learning that is social (Brown, 2005; Jamieson, Fisher, Gilding, Taylor \& Trevitt, 2000). There are at least three arguments for strengthening the collaborative or interpersonal quality of educational practice. The first is promoted by many employers. They may claim that graduates enter the workplace poorly prepared for coordinating their thinking with others (CBI, 2009). This suggests a need for educational environments that support experience in team work. The second argument for extending the 'social' dimension of learning is suggested by young peoples' vigorous engagement with internet-based social media. As so much curricular material is now accessed through the internet, it is natural to consider whether networked social media could also animate communication for learning. Such ambitions would give educational practice a stronger social and 'participative' quality. Then, if learning is made social within the virtual learning spaces of the internet, it is natural to extend such design thinking to the more 
physical spaces of the institutional campus: they also might become contexts for cultivating learning through social interaction and collaboration. Finally, the popular call for learning to have a more social quality resonates well with social constructivist theories of knowledge (Berger \& Luckman, 1966) and with conceptions of knowing as cognitively and socially 'distributed' (Clark, 1997). This perspective in turn complements psychological theories that stress the communual contexts of learning (Lave \& Wenger, 1990; Rogoff, 2003). In this climate of thinking, educational institutions will consider how they best 'socialise' their environments: thereby meeting the pleas of industry, the imperatives of theory, and the communication appetites of their students.

Where teachers are encouraged to "guide from the side” (King, 1995), the design of a more socialised university learning environment is likely to cultivate the potential of peerbased encounters. Yet undergraduate students are not always enthusiastic for collaboration in group work (Keely \& Shemberg, 1995; Underwood, 2003). This may reflect a tension between encouragement to study collaboratively while being assessed through individualised testing. Or it may reflect the documented difficulty of achieving productivity in group encounters (Kerr \& Tindale, 2004). However, it may be possible to design for less structured approaches to peer-based study. Accordingly, some commentators encourage more attention to the architecture and design of places-for-learning (Goodyear, 2008; Temple, 2007). The area of an educational campus that has been most vigorously re-visited in this spirit is the library (Oblinger, 2006). Some librarians uneasily predict that their "buildings will disappear over the next 100 years” (Wisner, 2001, p. 68). While others have identified an opportunity for re-configuring those buildings to accommodate not only digital resources, but a more socially interactive notion of study and research (Bennett, 2003; Demas, 2005). So, to the regret of some commentators (cf. Gayton, 2008), libraries increasingly offer space and 
furniture that supports collaborative interaction but also technologies that might mediate these exchanges in fresh ways.

Such new spaces have attracted attention from researchers documenting how they are used (Hunley \& Schaller, 2006). A simple basis for evaluation is footfall. However, some studies go further: conducting attitude surveys and interviews with users (e.g., Anders, Calder, Elder \& Logan, 2009). Yet there remains little direct observation of what students actually do in these spaces. An exception is a report by Bryant Matthews and Walton (2009). In their study, an observer occupied an open/social learning space in a university library. Careful attention to behaviour and movements furnished a sense of how students related to this place and its affordances. Even though the space observed was designed to encourage social exchange, many students were observed working independently - a situation the researchers found “curious” (p.11). However, they did observe collaborative work, along with numerous more unplanned social encounters. They also commented on the existence of a "tacit code of etiquette" (p.15), although this was not characterised in detail.

The present research extends these findings by observing a similarly open library space, but one which was more fully equipped with technologies designed to mediate collaboration (a mix of large screens, whiteboards, various working surfaces, and comfortable seating). Our research concern is to document the varieties of social interaction that arise in such an area and, in particular, to assess how far it conforms to a traditional vision of peer collaboration. That is, a vision invoking relatively intimate joint problem solving, defined as “. . mutual engagement of participants in a coordinated effort to solve the problem together"' (Rochelle and Teasley, 1995, p.70). We wish to understand more of how the actual social interactions in the present variety of learning space support or impede the experience of study and how, with experience, students self-organise their activity within learning spaces with strong affordances for social exchange. Other commentators have illustrated how social 
connectivities across parallel sites of learning can forge a productive 'polycontextual' integration in the learner's experience (Moll \& Greenberg, 1960). We wish to locate new forms of library design within this theoretical theme.

Student activity in the space considered here was documented by direct observation. However, other methods allowed students' use of this space to be understood in relation to broader out-of-class private study patterns. By capturing vivid accounts of study practices as both social and solitary arrangements, we hope to inform the effective design of institutional facilities that are both supportive and inspirational of learning. In more specific terms, we will determine how a representative open/social learning space is used, the role that technologies play in that use, and the effectiveness of this design for supporting diversity of study preferences.

\section{Method}

Here the open learning context is described followed by an outline of four research methods to capture study activities in this space.

\section{Context}

The context was a UK university with a contained campus on the edge of its city. Fieldwork occurred in the Arts and Social Sciences library which was accessible 24/7. Despite its discipline specialisms, this building was the largest and most central library and so was widely used. Our work occurred in the basement level area of a main library, open to all students (the "Hub”). Rooms for small group work were provided (although not observed in this study) while at its heart was a large space for communal study. This space was intended to support collaborative and group work but in a form that could be more fluid. The space offered familiar seat-and-desk facilities but also comfortable chairs and sofas aligned with low tables. As elsewhere in this liberary, personal computers could be used but networked computers were widely available, on both a long term (fixed) and short term (loan) basis. 
Moreover, large plasma screens encouraged informal group work in comfortable conditions and a number of whiteboards were similarly placed. The distinctive feature of technology prvisioin in this space was the expectation that it would be a site for collaboration. Finally, there was one multi-screen system that allowed dynamic management of writing and projection spaces for a contained group of students, including facilities to interact with the same system at a second remote campus site.

\section{Procedures}

Fieldwork took place over 10 days spread across four weeks before and during end-of-year examinations. Prior to starting, notices were displayed announcing the presence of a researcher across the specified dates. Student activity and attitude data were collected according to the following four methods. All student participants were opportunity sampled and received cafeteria vouchers as inconvenience allowances. Of those approached to take part in self-accounting methods below, only one student declined.

(1) Audio Diaries: to capture the broad profile of private study practices. Eight students were asked to keep an audio diary over 7 days, to record study activities. A small voice recorder was loaned along with guidance encouraging them to record summaries and reflections upon private study sessions. These reflections should include the context, the outcome, and the emotions associated with study.

(2) Behavioural observations: to generate objective behavioural records, randomly sampled across library users of this space and carried out in the traditional style of ethology. Observations took place over seven days comprising 'sessions', each lasting one hour and 20 minutes. There were 19 x 80-minute observations sessions. Two occurred in the evening and the remaining 17 in the day. The space was divided into four observation areas to ensure comprehensive coverage: a single observation session thus comprised four 20-minute 'cycles' 
of recording. The activity of each student in an area was scan-sampled (Altmann, 1974) four times, once every five minutes. A laptop was used to manipulate a visual map of the space which was constructed afresh in a PowerPoint file for each observation cycle. Numbered, moveable icons recorded the location of each student and notes were made using the PowerPoint note-taking tool. Four pilot sessions were conducted to perfect the management of this method. Six categories of activity were distinguished according to prior discussion and confirmed by the pilot observations. These are shown in Table 1, which also shows the subcategories that were coded in each case. Finally, once during each observation cycle, the number of students was counted - both in this area and on the two other floors of the library where conventional private study space was provided.

(3) On-task conversations: to explore motives and processes of study through short exchanges with spot-sampled students. Five students working alone and six groups of students working together were approached. They were asked:

1.What are you doing right now? What resources have you used?

2. Did you plan to come here? Do you do this regularly? Why this particular spot? Is it working?

3. How have you organised study? Have you been distracted? How do you control that?

4. Do you convene here regularly? With other people? Is it your favourite space? Why here?

(4) Focus groups: to discuss the experience of working in this space. Six groups of students comprising between four and six individuals were approached based on their co-location in a space. Discussions took place in a room near that space and were recorded by agreement and following the signing of research consent forms. Conversation was constructed around the following six themes:

1. The suitability and appeal of the environmental design 
2. The case for extending the availability of this space design

3. The selection and management of personal working areas

4. The management of distraction from surrounding student activity

5. Other study spaces used

6. Use made of resources in this space

\section{Analysis}

Analysis adopted a top-down approach. Finer level activity categories were derived from a grounded analysis of the unstructured but reflective (audio) diaries, in which comprehensive private study choices and outcomes were documented. Then, study activity in the open learning Hub area is described by direct observation of activities and analysis of the on-site conversations with students. Finally, the impressions arising from these records are integrated with discursive material derived from group discussion with regular users of this space. These data sources were systematised as follows.

Behavioural data were transcribed from field recorded forms and organised into a spreadsheet of categories, codes, and notes. Focus group tapes and audio diary tapes were both fully transcribed. Spot conversation records took the form of field notes, where verbatim comments were mixed with precise summary. Thereafter the following strategy was adopted:

(1) Audio diaries. students had been encouraged to find their own frame of references for summarising a private study session. Their transcripts were read several times, each time refining research notes that summarised the principle themes of concern being articulated by individual participants. From these notes the following organising themes were extracted as apparent within at least half of the recorded commentaries: (a) quality of the environment; (b) reported interactions with either material or social features of that environment; (c) study 
tensions reported as arising from specifics of the environment; (d) study opportunities reported as afforded by specifics of the environment; (e) personal strategies of adapting to the environment; (f) self-monitoring reflections on study activity; (g) overall evaluation of the study session. The diarists' words for commenting on each of these were coded in relation to these themes with the distinctions expressed in chosen codes tested against new transcript material in an iterative manner.

(2) Behavioural categories: a set of salient behavioural categories was specified in advance of the fieldwork. These categories were based on the overarching concern of the research project (forms of social exchange, mobility and private study ), pilot observation, and the affordances of the space design. These are described in Table 1: occurrences were counted and subjected to descriptive statistical summary.

\section{--- Insert Table 1 about here ---}

(3) On-task conversations: answers to each question were organised verbatim into a spreadsheet. Answers fell into a small number of categories dictated by the concern of the questions. These are reported below in largely verbatim terms.

(4) Focus groups: The relatively un-researched character of the situation observed dictated that a grounded approach was taken toward identifying the themes arising in student reflection. However, the extraction of that thematic structure was guided by reference to the categories identified in the analysis of audio diaries. In this way, all transcribed material was classified in relation to its apparent concerns, and complemented by a set of interpretative notes. Material was then gathered into a coherent set of themes. As the analysis progressed these themes were tested against new transcript material and with reference to the accumulating notes. In short, this process was partly driven by those hypotheses that had become visible through researcher immersion in this process but also by reference to 
distinctions draw from the other three sets of data. Finally, talk that strongly expressed dominant themes was extracted for illustrative purposes.

\section{Results and Discussion}

Findings from audio diaries will be described first. They provide a general perspective on the relationship between study practice and environments, as well as highlighting the terms in which students evaluated their ongoing study more broadly. We will then organise our aggregate findings under six headings that provide a solid framework for describing the situated experience of private study.

\section{Audio diaries: General patterns of student private study}

Diarists were vigorous in record keeping. Over 10,000 words were transcribed from 151 entries reflecting on 82 discrete private study sessions. Thirty-nine of these were in the open library space. The remainder were elsewhere in the library or in personal rooms at home. Although the participant sample is small, opportunity invitations to take part were not typically declined and the scale and care of the recording suggest the data provided were robust. The main conclusions are as follows:

Private study was seen as effective. The study sessions that received an overall outcome evaluation (32\% of the total) were generally judged in positive or successful terms (77\%).

Progress was judged against environments. In negotiating the conditions of diarykeeping, we stressed our interest in the experience of personal study in general, and not just in relation to space. Yet, specific reflections on the progress of studying were almost always $(67 \%)$ in relation to the environment (three times more often than to factors intrinsic to the individual, such as stress or procrastination). 
Environments understood as social. Where the quality of the environment was noted (67\% of sessions), it was almost always in terms of social features rather than physical comfort or other more material resourcing. Thus, social noise was mentioned in $45 \%$ of judgements, and occupancy levels in 31\%.

Environments experienced as disrupting. The environment was more likely to be described as a source of tension for study rather than a source of opportunities. Almost all (74\%) of those tensions related to the issue of distraction: $31 \%$ arising from general social noise but $43 \%$ from personal interactions with the student's own companions or peers. Where environment-based opportunities were mentioned $(\mathrm{N}=10)$, four were in terms of silence, two in terms of collaborating peers, but three in terms of friends not being present. Only one session was commented on in terms of a useful material resource in the environment - a whiteboard.

\section{Hub area observation}

These (Hub-using) diarists (above) offer a general snapshot of study practices across contexts. It is one that highlights the saliency of environments and, in particular, their social qualities rather than aspects of comfort or technical resourcing. From behavioural observations of such private study in the Hub, the following conclusions are possible.

Relative occupancy. The number of students using the Hub ranged between 52 and 192. Our systematic audit of other library areas revealed that this represented, on average, $16 \%$ of students studying in the building. Casual observation of these areas indicated that study in them was typically private and typically silent (as encouraged by traditional library rules). In judging the social dimension of Hub study, (standing) students using fixed service PCs were excluded as these invariably involved solitary (and often transient) activities.

Hub students engaged with others half the time. Social activity in the open seating 
areas is summarised from the ethological observations in Table 2. This table shows that a given student was about equally likely to be involved in silent activity as in conversational activity. Where conversation was occurring, it was split around 2:1 between talk with a specific peer versus talk within a group.

\section{--- Insert Table 2 about here ---}

Hub study involves traditional learning resources. Engagement with such 'social resources' can be compared with the use of other study resources (Table 3). Group discussion is relatively rare and much apparent study engagement centres on pen and paper or PC. The most contentious classification must be 'no study activity'. It includes situations of telephoning, texting, watching TV, reading a newspaper or seeming to engage in casual chat to friends and passers-by. It should be stressed that the coding took into account a continuous monitoring of activity and it was often made in fairly close proximity. This imparts some degree of confidence to coding this difficult case. Otherwise, pen and paper continues to be the dominant resource within study. High technology writing and projection tools were rarely in use for study.

--- Insert Table 3 about here ---

The Hub space is appealing, if distracting. Our 'on-task conversations' allowed further exploration of the content and progress of study activities with both solitary students $(n=5)$ and groups $(n=6)$. All students bar one had planned to work there that day. There was a strong sense of satisfaction with study. Everyone reported that it was working well at that moment and that they were happy with their progress. The reasons for choosing their particular location in the Hub were sometimes constrained by availability but if there were practical reasons, they had to do with working surface space - not access to technology - nor was reference made to a special appeal of the furniture, lighting, or views. Over half (55\%) 
admitted that they had experienced distractions. This was a mixture of other peoples' noise or their own temptation to chat or to surf the internet. The only specific remedy identified was putting on music headphones. There was universal admission that this study area was their favourite place to work - although several students qualified that in terms of 'for exam revision'. It was preferred over other informal public places on the grounds that there was more control over self-distraction and a relatively lower level of noise.

\section{Hub: students reflections on studying}

Our findings so far characterise this open learning space as popular although not evidently a rich site of collaborative working or engagement with group technologies. Moreover, the preoccupation of students with environmental distractions to study - and their frequently social nature - render these designs of study space potentially problematic. These themes will be explored in what follows through considering the experience of regular users of the space - taking account of the insights documented above from more direct observation. Analysis of these conversations suggested that student reaction to the Hub could be systematised around six overarching themes. Macro- and micro- spatial perception, space as social and as collaborative, engagement with tools, and individual study preferences. Illustrative quotes are included with an indication of the focus group source or the diarist number.

(1) Macro-spatial perception. While the Hub was popular, most students declared that their private study took place in a range of places. They admitted that choices depended on the nature of the work required: the intensity of that work (and thus the need for seclusion) or the extent to which progress benefited from discussion with others. It would often be acknowledged that demanding work would lead to study in a more silent part of the library: 
The idea that some work benefits from conversation and that this part of the library furnishes an opportunity for talking is typically expressed thus:

I generally tend to think of it that if I am doing group work or specifically trying to do something where I want to speak to another person or learn with another person specifically, I'll come down here. But if in general if I'm by myself, just self-revision or studying, I'll go into one of the smaller spaces upstairs (FG 5)

In other words, the Hub exists on a menu of space opportunities but it is an item that is often considered in terms of its potential for conversational study. While this might also be achieved in a domestic environment, this library space is typically seen as offering an optimal mix of potential to talk yet protective of more powerful forces to pull the student totally away from study:

It's quite a distraction at home though, isn't it? There's always people downstairs watching TV (FG 1)

(2) Micro-spatial perception. Students’ relationships with the finer detail of space and furniture was a very prominent concern. There was recognition of the core idea of flexibility, particularly as it applied to the options for working in groups:

I think it's quite nice that you can move the tables around downstairs and seats, like depending on sometimes there's three of us, sometimes there's six of us, so you can move around to fit how many of you want to sit together as well (FG 2)

Less was said about the features that made this furniture comfortable. In fact, the coffee shop quality of some seating design could be viewed as unhelpful, in that it was at the expense of more traditional working space:

I agree about the desks here, especially the really low ones which are just like, they're nice to just chill out and read your book or whatever, but when you actually need to work it would be good to have a few more of the proper height ones without the really low chairs. They're comfy, but it's not very practical for working (FG 1)

On the other hand, the net result of this design was widely approved of. So, a commonly expressed attitude towards the Hub was a welcoming of its apparently more laissez-faire 
conception and, in particular, its spacious and open quality, coupled with its atmosphere of natural movement and conversation: Yet the ability to design this openness can only be made possible by reducing the proportion of floor area that is given over to traditional working surfaces. Given the popularity of the Hub, this inevitably creates tensions over rational and equitable access to a limited supply of study furniture:

Basically there was a girl using a big table with some guy and I think it was like the small table was for mouse usage, it was basically a large mouse pad and we didn't have any table and we were like 'Can we use it?' and they were like 'Errrr, no!' (FG 3)

Unfortunately, experiences of this pressure for access can sometimes give rise to scepticism around the principle of open space and a hankering for more traditional work designs:

I don't know what the aim of the place was; to maybe have it more spacious and more ability to like free thinking and whatever. But I think people just want to work. It looks very nice, but I think people would prefer for it to be more practical (FG 5)

However, the issue discussed with greatest animation was the practice of students reserving scarce space with left belongings:

There was one time we came in and I had to sit on the floor and there was just this desk with stuff, loads and loads of stuff on the desk and on the seats and we were there for a couple of hours and noone came back to it. So it's like we could have been sitting there if they'd taken their stuff and then come back (FG 5)

This is not a problem that is unique to the Hub area of the library, as was sometimes acknowledged. However, the popularity of this particular area exacerbated the situation and led to strong feelings of frustration and annoyance:

It annoys me more the overnight thing and then they bowl in at like half eleven in the morning and you've got up at seven specifically to come and get space (FG 1)

Nevertheless, some students were happy to acknowledge their own attraction to territorial preferences and the common practice of territorial marking. Indeed students often felt their effort in claiming territory gave them natural rights: 
I really like having one desk for the entire day and not sort of having to move three times because I chose to go to the bookshop, or go home for tea and then come back in. I don't know, I think then, well, you were there at 9, I've got a table, you've only like rocked up at 3. I'm sorry, I rule (FG 4)

This strongly-recognised set of problems inevitably gave rise to an implicit set of rules and manners evolved to govern the management of space. Some of these were widely endorsed:

it's like a silent policy, whoever gets there earliest has made the effort, so you kind of have to respect that (FG 1)

(3) Space for collaboration. There was general acceptance that the area was very suitable for collaboration. It was common for students to invoke the general principle of bouncing ideas off each other (FG 4). It was also recognised that this was not a mode of study that was naturally sustainable. While more concentrated group work could sometimes be going on, the collaborative potential of the space was formulated often as something to be dropped in and out of:

I do do the discussion thing though ... the way I learn best is if I like read or cover something and then I explain it to someone else, because you have to know it to explain it and like I'll just tell her things. She doesn't know what they are but I'll just say them - just to reinforce the fact that I know it (FG 3)

Some students mixed their study between different parts of the library - seeing the Hub as a place where they would specifically come to study with others:

Like testing each other and stuff. That's what we do sometimes, like we'll work in a certain area but we'll come downstairs to like discuss a module or like a lecture or something (FG 1)

This is made possible, of course, by the lack of any strong rules constraining talking with others in this space. But it is also supported by the provision of shared tools:

I think it offers a different way of doing it, because if I've got a group coursework with four people at 4,000 words, originally I'd be more inclined to say 'You're doing this, that, 1,000, 1,000, 1,000,' just split it up equally, whereas with something like that you're more able to say 'Let's all just do it together and we can all write it out together.' We can all see the same screen and it's big and we can all sit around a big table rather than al, sitting around a desk like this with our four laptops effectively doing our own bit of coursework. It allows you to be a bit more collective. (FG 2)

It cannot be judged confidently from these conversations how widespread is this conception of collaborative study. However, whatever the depth of collaboration, informants did suggest 
that the space was experienced, in some broader sense, as a strongly social study environment. This is considered next.

(4) Space as social. Evidently, the central tension in a socially-oriented library space is unwanted overlap between other peoples' social activity and one’s own study (whether that study is itself social or whether it is intended to be private). This was sometimes expressed as a genuine ambivalence about the open space ideal:

It's actually good that you have that spaciousness, I'd like to have that but maybe in a more studious environment. Because it does very often happen that this area isn't where they do their main studying, so like often people are just sort of chatting amongst themselves about what they did over the weekend or meeting friends or whatever, which is great and obviously it is like a non-silent study area, but it does mean that if you do actually come here to study then it's more difficult to focus. (FG 4)

Such off-task noise is felt more keenly to be unacceptable and, indeed, it may be all the more distracting:

No, I don't mind noise, it's more sort of like people not studying, I find that really distracting (FG 4)

Yet there are no clear principles or rules that govern what is permissible and that give students a basis for managing intrusion:

When they were playing a Formula 1 on the big screen with the volume out, I thought that was a little bit excessive (FG 3)

like if you're here at 8 or 9 o'clock at night, people then start to get like a bit silly and there's no kind of control over it and there's no like exact knowing of how silent like the place is supposed to be, because you are allowed to talk, but, you know, screaming is not really on (FG 5)

On the other hand, this has to be set against an apparent appetite that many students expressed for a cultivated non-silent atmosphere:

Yes, lots of people say they can't work in silence, so that's why they come down here, just for the, like the kind of background (FG 1)

I like working with a bit of background noise as long as it's not too loud that my attention goes towards it. I find in complete silence then I can't really concentrate (FG 4) 
Alternatively, some students need a kind of social buzz but they realised it in a more intermittent pattern, as in valuing the opportunity to shift between private study and social chat:

Yes, definitely. I need that, I need someone to like talk to in my breaks because otherwise I'll just get bored and leave(FG 1)

I was alone for most of the day, although that probably should have made me work better, it did in short bursts. However I'd get easily bored because there was no-one to talk to next to me. So I'd kind of go off in search of my other friends who were up in silent study. So I found that although I did work harder - in short bursts - that I'd get bored, probably lonely, quite quickly (Diary 6)

For some, social noise rises to unacceptable levels and because the implicit contract of using this area does not easily warrant complaining about this, students have to find other solutions. One is simply to leave the space, as the library does provide silent alternatives:

like you'll get a couple of people that have slightly annoying voices and speak really loudly right next to you. That's quite annoying... you take that with coming down here. If you want silence you should just go upstairs (FG 1)

An alternative favoured by many is to make private noise, by inserting headphones and listening to music:

I like the background noise, so I like it, to come downstairs assuming that it's not going to be too noisy and then when it gets to the point where it's really noisy that's when I kind of put my iPod on and try and like zone out (FG 5)

The freedom to talk can evidently be both an opportunity and a nuisance. However, the social quality of the Hub experience is not solely to be understood in terms of conversations. There is a 'presence' factor which students often mentioned as an important source of motivation, or even an inspiration, by virtue of the examples of working it makes visible:

So usually your friends are with you as well, so as long as they're working as well then that like encourages you to do it more (FG 3)

I think when one person starts working people generally do and because we're all friends we kind of join in the same discussion, but like at the end of the day I reckon we probably work maybe solidly for an hour and then chat for like 15-20 minutes (FG 3) 
Nevertheless, the other side of social presence is self-consciousness and although it was not mentioned often in our conversations, it is possible that some students are inhibited from freely using the space on this basis:

One of our friends says that she won't sit downstairs on her own, but she doesn't mind sitting upstairs on her own... I think because it seems a social space it makes her look like she's got no friends if she's on her own and she's not comfortable with that. (FG 3)

(5) Tools. Design of new library spaces is typically motivated by an ambition to furnish new tools and technologies for joint knowledge construction. Evidently networked computers are a key and generic tool in this sense and their availability was universally welcomed, even if the access involved a mixed pattern of use:

Downstairs, having the choice to bring your laptop, like even if you only use it to listen to music or something, or to have 20-minute breaks and just mess around and then carry on working again (FG 3)

A distinctive resource for potential collaboration is the whiteboard. Generously provided, these were rarely mentioned spontaneously in discussion, while prompts to consider them suggested a limited pattern of engagement. Some students did see the attraction of this resource - particularly in relation to expressing the visual demands of some science subjects:

We've used the whiteboards occasionally last year for drawing chemistry mechanisms, like where you really only learn them by sort of drawing out lots of different varieties. That's quite good, being able to bounce ideas off each other, because one person can then possibly spot where you've gone wrong and then shout it out and then change it (FG 4)

However, others were more sceptical. A common observation was that the areas where the boards were accessible often involved attractive seating that was taken by students simply wanting to be in that area for general study:

where we're sitting at the moment, there's a huge white thing behind us and like we're not using it, but no-one else can because it's like blocked by like a row of four seats and three tables (FG 1)

People use the big screens as a computer. It's just used as another computer. You don't necessarily need a big screen that has this touch stuff. (FG5)

Challenging this misappropriation of space seemed not to be in the informal etiquette: 
I'd really like to say like 'Yes, you can use it', but no, I actually wouldn't. (FG3)

Yes. I think that is a really annoying thing, but at the end of the day like you'd do the same, like you don't go up to anyone and say 'Do you mind moving?' because if someone came up to you, you know perfectly well that you'd say.. So it's kind of a mutual selfishness. (FG5)

(6) Individual preferences and practices. Many themes discussed above involve students articulating their preferred modes of study or the habits that they believe help them get their work done. In expressing matters in this personalised way, the four most common themes were: distraction, ambience, social contact, and the scaffolding of commitment. The positive aspects of the space were commonly expressed in terms of its relaxed ambience and its potential for working with others:

I like it to be more relaxed. It's the way I work, it's just easier for me personally. I just like to be able to sit down, not take it too seriously, not get too bogged down in it sort of thing, because I just, it just helps me (FG 6)

Students differed in how they regarded the higher noise levels in this space. For some it was a positive advantage to working there, for others it became irritating. Students often identified their study practices in relation to this sensitivity to (or tolerance of) distraction. However, this was part of a very general orientation towards distraction. As an obstacle to study, it was not always projected onto the external environment - as something that people in a particular place do to you. Rather it was often identified as a vulnerability of the individual, something they had poor control over.

One solution was to allocate different kinds of study demand to different environments. Within such a strategy it was common to see the relaxed ambience of the Hub space as very attractive for a certain type of work while urgent or intense study would need to be done elsewhere:

I think now for this stuff that I'm doing I'd rather be here because I'm just sort of reading a whole load of different papers and trying to get the general gist of a lot of things, so I find that works quite well 
here, but I know that once I'll actually be writing and wanting to like concentrate or proof reading a paper and things like that, I'll probably go to a quieter area (FG 4)

Another perspective was to regard distraction as something to be finely tuned. Aiming to work in the maximally distracting domestic environment was recognised as unrealistic. While the enforced management of distraction in a traditional library might sometimes seem just too unappealing to work. So the student might chose a moderately distracting environment such as the Hub, knowing that it would come at the cost of a longer total period of study:

I think I'd do the same amount of work that I'd do upstairs but obviously like in a longer period of time, like I know I come to the library from 9 'til 6, whereas if I sat upstairs I'd probably do it in a shorter space, but I kind of feel I work, like it suits me to work downstairs more than upstairs (FG 3)

\section{Conclusions}

We have observed an institutional space designed to attract student engagement with study and, in particular, to foster collaboration. That space was central on the campus and integrated with library resources. It offered generous work surfaces, comfortable furniture, and collaborative technologies. Yet, as reported by Bryant, Matthews and Walton (2009), we observe a significant proportion of apparently solitary study (Table 2). Nevertheless, the space is very popular: not because it is valued in terms of relatively superficial features such as its 'airport lounge' comfort and decor - it is valued very much in terms of its social quality but through a more articulated sense of the 'social'. However, our concern here is less to stress a lack of formal, intimate collaboration but more to highlight the significance of what we are calling a 'social ambiance' dimension of communal study. We suggest that this is a neglected but valued aspect of 'co-labour' for learning: one that encourages a more carefully articulated account of the sociality of study.

In these concluding remarks, we identify three points about this sociality. The first stresses that the experience of learning as 'collaborative' is not a singular thing and we offer 
a taxonomy of the collaborations that we observed. The second point stresses that institutions should design for a mix of study preferences. And third, students may need to be actively guided towards exploring that diversity of opportunity.

On the first point: we propose a more nuanced conception of the 'social' in learning. The present learning spaced design suggests four varieties of social engagement:.

1. Focused collaboration: Occasions of traditional, and relatively intense joint problem solving. These are likely to be planned and strongly outcome-oriented.

2. Intermittent exchange: whereby students convene for independent study that permits an occasional and improvised to-and-fro of questioning or commentary.

3. Serendipitous encounter. That is, chance meetings with peers in which study-related issues (and perhaps other matters) are discussed briefly and on the fly.

4. Ambient sociality: Students identify the importance of simply 'being there' as participants in a studying community.

This last format seems particularly potent and under-theorised. Therefore, we wish to foreground its importance here, It suggests an appetite for learning within a 'social ambience'. Students appeared to gain inspiration or reassurance from merely being among others they knew were in a shared predicament: that is, one of intentional and systematic learning (i.e., 'study’). The most salient distractions were surrounding peers (often anonymous) who were not themselves working. It seems this space offered a setting for focussed study that needed to be finely balanced. On the one hand, the presence of others gently disciplines one's own concentration: i.e., social support. On the other hand, that presence can create a seductive alternative to the demands of such concentration: i.e., social distraction. On the macro level, many students solve this by managing an 'economy' of study venue choices: one that manages the distractions latent within social support through making movements between different sorts of environment. Such distraction is more difficult to 
manage on the micro level: although one popular solution involved listening to music through earpieces.

That identifies our second concluding point. This analysis has implications for how institutions think about the design of spaces that best support social learning - as an experience that is grounded in the community of those institutions. Universities should explore provision of out-of-class study spaces that support the various forms of collaborative and solitary learning that we have identified here. Reviews of existing literature acknowledge that there is little research that clarifies what relationships might exist between the design of study spaces and the learning outcomes of students (Woolner et al., 2007). The present study provides no insight into any link of that kind. However, it does reveal that students themselves can perceive a positive benefit in having what might be termed a 'third place' (Oldenburg, 1999): somewhere between the recreational and informal spaces of everyday life and the traditionally structured spaces of work and study. Moje et al. (1992) had previously articulated the various ways in which such spaces allow a bridging across discourse communities as well as a space in which those discourses can be productively explored. .The construction of these spaces in young peoples' world has now been well documented by social geographers (e.g., Holloway \& Valentine, 2000), The deliberate design of third places has subsequently been pursued in early educational practice by embedding areas within the institution that afford the bringing together of in-school and out-of-school discourses (e.g., Cook, 2005). However, there is no reason to suppose that these spaces are only needed in early education: the observations of this study help position them within a higher education landscape. Our third point concerns how students are encouraged to engage with such opportunities. It is tempting to unpack this design challenge in terms of needing to respond to diverse study styles - an effort of 'personalising' learning. Although students spoke of their individual study preferences with a confidence that suggested the literature of 'learning 
styles', this should not imply the need to design towards such student preferences as if they were rigid, or trait-like. As Coffield, Mosley, Hall and Ecclestone (2004) argue in relation to learning styles, the challenge of such apparent preferences is to design for diversity but with the aim of resourcing individuals to explore alternative modes of learning - rather than only reinforcing entrenched preferences. In terms of preferences for study environments, this perhaps implies designing a mixed economy of space but also greater institutional guidance on ways of using it. The present observations were made at just one period of the year - the formal examination period - and observations were only made in the open format area of the new learning space. We expected that examinations would encourage more collaborative exchanges as students prepared for a common assessment experience. This seemed the ideal fit to aspirations for a more fluid and improvised form of collaborative working. The individualised nature of formal exams might seem to mitigate against collaboration but, as it happens, none of our conversations with students highlighted a 'private' disposition towards revision. It is true that libraries (including this one) provide more contained spaces for potentially more intense or intimate collaboration. But scarce library real estate means these can only serve small numbers. Our concern was always with the more open format departure in design - as this is a form that is being so widely adopted (Oblinger, 2006).

At the start of this report we identified a contemporary imperative for learning to have a stronger interpersonal dimension. In particular, it is now considered a priority to offer students opportunities to learn collaboratively. We also noted students' frequent resistance to such study patterns - an observation that may reflect the rigors of (apparently) competitive assessment regimes. Yet it might, in part, reflect the modest level of resourcing for collaborative engagements. However, resourcing need not be exclusively for focused collaboration of the kind associated with group projects. Indeed, that is not necessarily the pressure coming from employers, while organisational research stresses the uncertain 
advantages of such project work (West, Brodbeck \& Richter, 2004). Moreover, young users of digital technology are not working this way in their Web 2.0 communications: what they get up to is far more fragmented and loosely coupled. If institutions wish for a reference point to guide the design of material spaces for interaction, the virtual spaces of Web 2.0 might supply it. The emerging configuration of internet communication resources certainly offer designs for close and intense collaboration: yet they also offer resources for more improvised and intermittent exchange that is perhaps more coordination than collaboration. In their design of new learning spaces, institutions need to create something of this mixed economy but in bricks and mortar. This may thereby fashion a useful integration of material and digital space.

\section{References}

Altmann, J. (1974). Observational study of behavior: sampling methods. Behaviour, 49, 225267.

Anders, D., Calder, A., Elder, K., \& Logan, H. (2009). Investigating the dynamics of an integrated learning space at James Cook University. In D. Ratcliffe, H. Wilson, D. Powell \& B. Tibbetts (Eds.), Learning spaces in higher education: Positive outcomes by design (pp. 39-44). Brisbane: University of Queensland.

Bennett, S. (2003). Libraries designed for learning. Washington, D.C.: Council of Libraries and Information Resources.

Berger, P.L. \& Luckman, T. (1966). The social construction of reality: A treatise on the sociology of knowledge. Garden City, NY: Doubleday.

Brown, M. (2005). Learning spaces. In D. G. Oblinger \& J. L. Oblinger (Eds.), Educating the net generation (pp. 12.1-12.22). Washington: Educause.

Bryant, J., Matthews, G., \& Walton., G. (2009). Academic libraries and social and learning space: A case study of Loughborough University Library, UK. Journal of Librarianship and Information Science, 41, 7-18.

Clark, A. (1997). Being there: putting brain, body, and world together again. Cambridge Ma.: MIT Press.

Coffield, F., Moseley, D., Hall, E., \& Ecclestone, K. (2004). Learning styles and pedagogy in post-16 learning: A systematic and critical review. London: Learning and Skills Research Centre. 
Comber, C. \& Wall, D. (2001). The classroom environment: a framework for learning. In C. Paechter, R. Edwards, R. Harrison \& T. Twining (Eds.), Learning, space and identity (pp. 87-101). London: Paul Chapman Publishing.

Confederation of British Industry (2009). Future fit: preparing graduates for the world of work. London: Confederation of British Industry Higher Education Task Force.

Cook, M. (2005). 'A Place of their Own': Creating a classroom 'Third Space' to support a continuum of text construction between home and school. Literacy 39, 85-90.

Crook, C.K. \& Light, P. (2002). Virtualisation and the cultural practice of study. In S. Woolgar (Ed.), Virtual society? - technology, cyberbole, reality (pp. 153-175). Oxford: Oxford University Press.

Gayton, J. T. (2008). Academic Libraries: 'Social' or 'Communal?' The Nature and Future of Academic Libraries. The Journal of Academic Librarianship, 34, 60-66.

Goodyear, P. (2008). Flexible learning and the architecture of learning places. In M. Spector, D. Merrill, J. van Merrienboer, \& M. Driscoll, (Ed.), Handbook of research on educational communications and technology, (pp. 251-257). New York: Routledge.

Holloway,S. and Valentine, G. (Eds.) (2000). Children’s Geographies: Playing, Living and Learning, London: Routledge.

Hunley, S., \& Schaller, M. (2006). Assessing learning spaces. In D. G. Oblinger (Ed.), Learning spaces (pp. 13.1-13.11). Boulder, Co: Educause.

Jamieson, P., Fisher, K., Gilding, T., Taylor, P. G., \& Trevitt, C. (2000). Place and space in the design of new learning environments. Higher Education Research and Development, 19, 221-237.

Keeley, S. M. \& Shemberg, K. (1995). Coping with student resistance to critical thinking. College Teaching, 43, 40-146.

Kerr, N. L., \& Tindale, R. S. (2004). Small group decision making and performance. Annual Review of Psychology, 55, 623-656.

King, A. (1995). From sage on the stage to guide on the side. College Teaching, 41, 30-35.

Lave, J., \& Wenger, E. (1990). Situated learning: Legitimate peripheral participation. Cambridge. UK: Cambridge University Press.

Moje, E.B., Ciechanowski, K.M., Kramer, K., Ellis, L., Carrillo, R. and Collazo,T. (2004).Working toward Third Space in content area literacy: An examination of everyday funds of knowledge and discourse', Reading Research Quarterly 39, 40-70 Moll, L. C., \& Greenberg, J. B. (1990). Creating zones of possibilities: Combining social contexts for education. In L. Moll (Ed.), Vygotsky and education: Instructional implications and applications of sociohistorical psychology (pp.319-348). New York: Cambridge University Press.

Oblinger, D. (Ed.). (2006). Learning spaces. Boulder, Co: Educause.

Oldenburg, R. (1999). The great good place: Cafes, coffee shops, community centers, beauty parlors, general stores, bars, hangouts, and how they get you through the day. New York: Paragon House.

Rogoff, B. (2003). The cultural nature of human development. New York: Oxford University Press.

Roschelle, J. \& Teasley, S. (1995). The construction of shared knowledge in collaborative problem solving. In C. O'Malley, (Ed.), Computer Supported Collaborative Learning. (pp. 69-97).Heidelberg: Springer-Verlag.

Rudd, T., Morrison, J. \& Facer, K. (2006). What If... Re-imagining learning spaces. Bristol: Futurelab.

Ryan, S., Scott, B., Freeman, H. \& Patel, D. (2000), The virtual university: The internet and resource-based learning. London: Kogan Page. 
Temple, P. (2007). Learning spaces for the 21st Century. York: Higher Education Academy. Underwood, J. D. M. (2003). Student attitudes towards socially acceptable and unacceptable group working practices. British Journal of Psychology, 94, 319-337.

Wellman B., Haase A.Q., Witte J., \& Hampton K. (2001). Does the Internet increase, decrease, or supplement social capital? American Behavioral Scientist. 45, 436-55.

West, M.A., Brodbeck, F.C., \& Richter, A.W. (2004). Does the "Romance of Teams" exist? The effectiveness of teams in experimental and field settings, Journal of Occupational and Organizational Psychology, 77, 467-74.

Wisner, W.H. (2001). Librarianship enters the twilight, Library Journal, 126, 68.

Woolner, P., Hall, E., Higgins, S., McCaughey, C., \& Wall, K. (2007). A sound foundation? What we know about the impact of environments on learning and the implications for Building Schools for the Future. Oxford Review of Education, 33, 47-70. 
Tables

\begin{tabular}{|l|l|}
\hline \multicolumn{1}{|c|}{ Category } & \multicolumn{1}{c|}{ Codes } \\
\hline $\begin{array}{l}\text { Space (where the student } \\
\text { was) }\end{array}$ & $\begin{array}{l}\text { Short stay PC, Long stay PC, Thunderwall, Large monitor area, } \\
\text { Whiteboard area }\end{array}$ \\
\hline $\begin{array}{l}\text { Presence (position or } \\
\text { movement) }\end{array}$ & $\begin{array}{l}\text { Arriving, Present, Away (possessions remaining), Mobile, } \\
\text { Leaving, Left }\end{array}$ \\
\hline $\begin{array}{l}\text { Interaction (nature of } \\
\text { exchange with others) }\end{array}$ & $\begin{array}{l}\text { N/A (alone), None, Partner conversation (paired), All group } \\
\text { conversation, Specific group member conversation, Passerby } \\
\text { conversation, Absent from surrounding conversation }\end{array}$ \\
\hline $\begin{array}{l}\text { Study (engagement with } \\
\text { study) }\end{array}$ & $\begin{array}{l}\text { None (phone, eating, social chat, magazine, looking around, etc), } \\
\text { Group discussion, Pen/paper only, PC only, Pen/Paper plus PC, } \\
\text { Other equipment. }\end{array}$ \\
\hline Affect & Positive, Negative, Neutral \\
\hline Posture & $\begin{array}{l}\text { Standing, Seated, Reclining, Hunched/head down, Feet up, On } \\
\text { floor }\end{array}$ \\
\hline
\end{tabular}

Table 1: activity categories and their codes for scan sampling behavioural observation 


\begin{tabular}{|l|r|}
\hline \multicolumn{1}{|c|}{ Social interaction } & $\begin{array}{c}\text { \% cases in } \\
\text { free area }\end{array}$ \\
\hline No social interaction: seated alone & 29.4 \\
\hline No social interaction: although possible & 21.3 \\
\hline Conversation with partner & 21.6 \\
\hline Conversation with all group members & 15.5 \\
\hline $\begin{array}{l}\text { Conversation with specific group } \\
\text { member }\end{array}$ & 6.5 \\
\hline Conversation with passerby & 2.8 \\
\hline Absent from surrounding conversation & 2.9 \\
\hline
\end{tabular}

Table 2: Distribution of conversation in open seating area, excluding public PC use 


\begin{tabular}{|l|r|}
\hline \multicolumn{1}{|c|}{$\begin{array}{c}\text { Study Activity (free area } \\
\text { only) }\end{array}$} & \% cases \\
\hline No study activity & 27.6 \\
\hline Group discussion & 39.0 \\
\hline Pen and Paper & 18.3 \\
\hline PC only & 3.0 \\
\hline Pen/Paper + PC & 2.4 \\
\hline Whiteboard & \\
\hline
\end{tabular}

Table 3: Distribution of study resource use in open area 
Table Legends

Table 1: activity categories and their codes for scan sampling behavioural observation Table 2: Distribution of conversation in open seating area, excluding public PC use Table 3: Distribution of study resource use in open area 